\title{
Analysis of the causes of traction electric failures of electric cargo cars operated on railways of the Republic of Uzbekistan
}

\author{
Sardor Nuriddinov", Bobomurod Avazov, Fozil Hasanov, and Yulduz Rakhmonova \\ Tashkent State Transport University, Tashkent, Uzbekistan
}

\begin{abstract}
In this article, it is considered to analyze the reliability of TEM (traction electric machine) of electric locomotives of the railways of the Republic of Uzbekistan. To determine the damage, the most expedient and effective method will be to extend the life of the insulation by encapsulating local damage using impregnating materials and heat radiation. Over the past ten years, a stable tendency for insulation breakdown and turn-to-turn closure of the armature winding of the NB-514 type has been maintained in Unitary Enterprise (UE) "O'ztemiryo'Imashta'mir." In this regard, a hypothesis was put forward that insulation breakdowns and turn-to-turn short-circuit of the armature winding most often occur due to intense heat and mass exchange processes in the insulation of the frontal parts of their windings with open section heads.
\end{abstract}

\section{Introduction}

The traditional way to study the reliability of electrical machines is to study the statistics of failures. In the initial study of statistics of failures by types of electrical machines, the greatest attention is paid to "weak" nodes and causes of failures [20]. When investigating the reliability of systems or individual technical products, the following methods are used: the system is divided into blocks, then the reliability of each block and the resulting reliability of the entire system are determined.

The system is divided into blocks based on analyzing the functional purpose and physical processes occurring in the system and blocks. However, there is no point in examining all the blocks included in the system since their reliability usually varies significantly [19]. Failures of some of the units are practically impossible, and taking them into account in determining the resulting reliability only complicates experiments and calculations, practically without changing the final result. Therefore, when drawing up structural diagrams, the method of "weak links" is used, highlighting only those blocks, the reliability of which in these conditions is minimal.

\footnotetext{
* Corresponding author: boboyarovich@bk.ru
} 


\section{Methods}

In this aspect, we will consider the main types of electrical machines. In asynchronous motors, in the study for reliability, the stator winding and the bearing assembly should be singled out as "weak links." In synchronous machines, the stator and rotor windings, the brush apparatus and slip rings, bearings (or thrust bearings), cooling and fire extinguishing systems, etc., should be distinguished [1]. From the point of view of its reliability, a DC machine consists of the following assemblies: collector-brush and bearing assemblies, armature winding, excitation, additional poles, and compensation.

Failures of electrical machines can be divided into structural, technological (production), and operational. Structural failures arise due to imperfection (ignorance) or violation of the rules for the design and construction of an electric machine, technological failures due to a violation of the production or repair process, operational failures due to improper use, lack of protection, violations of the operating conditions of electrical machines. Failures of electrical machines can be caused by aging of materials and wear of components and random load concentration, which is almost impossible to predict[3].

Long and painstaking work on the collection of statistical data on failures and their analysis is necessary for the development and refinement of methods for calculating the reliability of electrical machines, ensuring and increasing reliability, improving manufacturing technology, developing the choice of electrical machines, creating and improving protection systems and rules for technical operation[2].

\section{Results and Discussion}

Let us analyze the causes of failures of electrical machines of various types.

Asynchronous motors. In the overwhelming majority of cases (85-95\%), failures of induction motors with power over $5 \mathrm{~kW}$ occur due to damage to the windings and are distributed as follows[5]:

- inter-turn closures - $88 \%$,

- breakdown of inter-phase insulation - 7\%,

- breakdown of groove insulation $-5 \%$.

The bearing assembly accounts for $6-9 \%$ of failures, and a small percentage is associated with such reasons as unsoldering the output ends, twisting of shafts, rupture of rotor bars, etc.

The reasons for the failures can be differentiated as follows [6]:

- technological - 38\%;

- operational (mainly unsatisfactory protection of electric motors) - $45 \%$

- structural - $17 \%$.

Unsatisfactory protection means the lack of thermal protection or its failure. Studies have shown that the spread of the response time of the thermal protection, even if it is not configured, practically does not affect the accident rate. When protecting electric motors with fusible rates, which is the case in most cases, they fail due to operation on two phases. Operational materials indicate that $80 \%$ of accidents (due to operation in two phases) are due to the lack of thermal protection and only $20 \%$ from its malfunction [8].

One of the common reasons for increased failure rates of electric motors is the unit's vibration, which leads to failures of bearings, windings, and sometimes cracks in the castiron casing of the electric motor and the legs the pedestal. The increased vibration is explained by the unsatisfactory articulation of the electric motor and the actuator, residual imbalance of the rotating masses, increased clearance between the rolling elements and the ball bearing rings, distortion of the shape of the bearing seats or their misalignment, oval shape of the ball bearing rings, etc. 
The process of destruction of insulation is accelerated by the concentration of loads: increased mechanical forces during transient processes, over current, overvoltage, vibration, and other factors. In this situation, the presence of areas with reduced electrical strength leads to damage to the winding since the amplitudes of practically possible overvoltages are insufficient for the breakdown of good-quality insulation. During the manufacture of the winding, ferromagnetic particles may fall on its surface, the vibration of which in a magnetic field leads to the gradual destruction of the insulation[9].

Insufficiently reliable fastening of the winding frontal parts creates a condition for insulation damage, mainly at the exit of the rods from the slots. Over time, the basket of the winding frontal parts is lowered. Therefore they appear more vulnerable to vibration and shock under the influence of sudden electrodynamic forces (short circuit and asynchronous switching on - starts and reversals for motors). The insulation of the winding is also subject to a serious risk in the event of thermal overloads caused by local causes. So, when the insulation of sheets is destroyed, and the segments of active steel are localized, the temperature in the closure area can reach $200-300{ }^{\circ} \mathrm{C}$. The penetration of water and oil into the machine also contributes to damage to the stator winding insulation.

The reason for the damage to the active steel is mainly the weakening of its pressing. Pressing of steel should be done after about $0.5 \mathrm{~mm}$, and the pressing pressure increases from $80-100$ to $179 \mathrm{~N} / \mathrm{cm}^{2}$ [7]. At lower pressures, the required pressing density is not ensured. There is a risk of damage to the varnish film under the ventilation struts at higher pressures, where local pressures reach $1000-1200 \mathrm{~N} / \mathrm{cm}^{2}$.

Relatively rare but severe accidents are caused by the destruction of rotor shafts. The cause of the accident can be rotor jamming when the rim breaks, cracks propagation from the teeth into the shaft depth, and temperature stresses in the rotor body caused by an asymmetric distribution of heat fluxes in the cross-sectional plane. For example, the temperature difference between the surface of a large tooth and the inner region of the rotor at the neutral axis in turbochargers with indirect cooling reaches $90-100^{\circ} \mathrm{C}$. In this case, the breaking stress directed along the rotor axis can be of the order of $16,000-180,000 \mathrm{~N} /$ $\mathrm{cm}^{2}[10]$.

A common malfunction is a decrease in the insulation resistance of the rotor circuit due to contamination of the conductor with oil and coal dust. A decrease in the insulation resistance can also occur due to contamination of the winding itself.

Most often, damage to bearings and thrust bearings is accompanied by the melting of Babbitt, damage to the liners and pins by bearing currents, and oil leakage. Smelting of Babbitt usually occurs as a result of a malfunction of the oil supply system.

When the unit stops quickly, the damage to the pins is negligible since the molten Babbitt acts as a lubricant. Damaged liners must be replaced or refilled. Bearing currents are typical for large electrical machines. Very significant currents flow through the bearings when the excitation circuit is closed to the housing, and there is a ground in the outer rotor circuit. In this case, the damage to the shaft journals and bearing shells can be very serious. However, even small bearing currents with prolonged flow lead to damage to the liners and shaft journals.

A very important unit of hydro generators is the thrust bearing. Bearing damage is responsible for a significant failure rate for this type of electrical machine [12]. The most typical damages to thrust bearings are wear, scuffing, and melting of the Babbitt layer on the surface of the segments and damage from bearing currents. The excessive specific load can cause increased wear in certain areas of the segment surface, caused by their thermal deformation or other reasons.

Increased vibration of electrical machines indicates the presence of design flaws, manufacturing and assembly defects, and damage. At the same time, vibration itself is a source of serious damage and accidents [11]. 
As a result of increased vibration, there is a weakening of the compaction of active steel, violation of the density of joints, destruction of welded seams and parts due to material fatigue and contact corrosion, a decrease in gas tightness, accelerated wear of insulation, leakage in water and oil supply systems, increased losses and heating of bearings, malfunction and wear of slip rings and brushes, etc.

As a result of the analysis of statistical data on failures of traction electric motors of direct current of heavy-duty electric locomotives, the establishment of TEM (traction electric motors) NB-514 established that the most unreliable elements are the armature winding and the collector -brush assembly. According to the analysis, the number of electric motor failures in the collector-brush assembly ranges from $41.6 \%$ (for the enterprises of UE "O'ztemiryo'lmashta'mir") and on average for all industries is $26.5 \%$; on the armature winding - from $21.6 \%$ (UE "O'ztemiryo'lmashta'mir") to $44.2 \%$ [14].

Consider the typical damage to the main components of DC machines. Typical damage to the collector includes a change in its shape due to uneven wear, a violation of the surface polishing with the appearance of scratches on it, burning and melting of the plates with unfavorable switching and circular lights. If one of the specified damage occurs, the machine must be stopped to carry out appropriate repairs.

Damage to the armature winding occurs for the following reasons [13]:

- due to the breakdown of the housing insulation between the winding and the armature steel package,

- turn-to-turn closures (in anchors with multi-turn sections),

- de-soldering the connecting top of the collector plates with winding (in high-power machines),

- destruction of the bands holding the armature winding (in high-speed machines), etc. Damage to field windings, auxiliary pole windings, and compensation windings is quite rare.

They are usually a breakdown of the housing insulation between the winding and the magnetic system of the machine.

Of the mechanical parts of DC machines, plain or rolling bearings and shaft journals are most susceptible to wear. Typical signs of damage to these units are wear of the liners, grease leakage, malfunction of the lubricating rings, breakage of balls or rollers, destruction of cages, jamming of balls, jamming of the shaft journals in the bearing liners, etc. In a bearing or other device, a disorder in adjusting the position of the brush holders on the fingers or traverse brackets, damage to the fingers or brackets that hold the brush holders on the traverse, etc. The occurrence of any of these damage results in the failure of the machine, which must be stopped to carry out appropriate repairs [16].

Figure 1 shows a fragment of typical local damage to the insulation of the frontal part of the armature winding TEM (traction electric machine) NB-514 from the side opposite to the collector. 


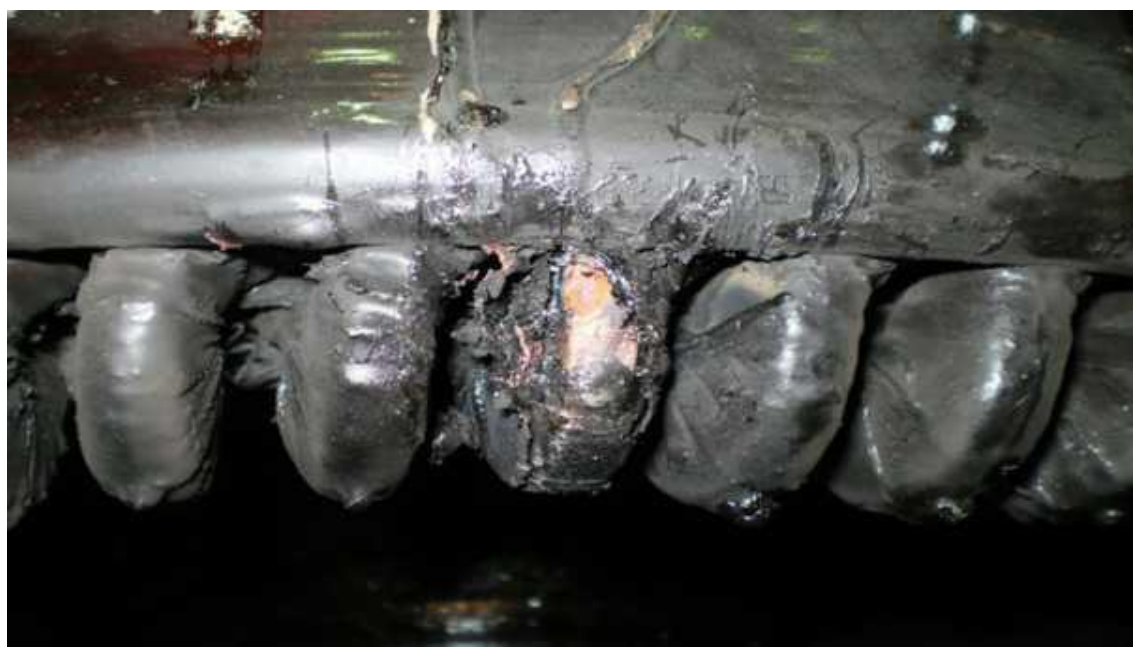

Fig. 1. Fragment of damaged insulation on the frontal part armature winding electric machine

With such damage, the most expedient and effective method will be to extend the life of the insulation by encapsulating local damage using impregnating materials and heat radiation.

Over the past ten years, Unitary Enterprise (UE) "O'ztemiryo'lmashta'mir" maintains a stable tendency for insulation breakdown and turn-to-turn closure of the armature winding of TEM (traction electric motors) type NB-514. In this regard, a hypothesis was put forward that insulation breakdowns and turn-to-turn short-circuit of the armature winding most often occur due to intense heat and mass exchange processes in the insulation of the frontal parts of their windings with open section heads. Since these engines operate in harsh environmental conditions (rain, snow, temperature changes, etc.) [3, 4]

The quality of electrical machines is a set of properties that determine their suitability for use. Reliability is the most important technical and economic indicator of any technical device's quality, particularly an electric machine, which determines its ability to operate without fail with constant technical characteristics for a given period of time under certain operating conditions[15]. With the widespread use of electric machines in various systems of electric drives and automatic control of production, the reliability of these machines is largely determined. Failures of electrical machines cause significant material damage. Improving the reliability of electrical machines, the output of which is tens of thousands of products per year is the most important scientific and technical problem.

The problem of the reliability of technical systems over the past two to three decades has sharply exacerbated, which is explained by the following objective reasons [17]:

- a sharp increase in the complexity of technical systems, including hundreds of thousands and even millions of individual nodes and elements;

- extreme conditions in which the TEM (traction electric machine) is operated (high speeds, significant accelerations, high temperatures and pressures, vibration, temperature differences, etc.);

- the intensity of the operating modes of the system or individual units (at high temperatures, rotational speeds, pressures, current density, etc.);

- increasing requirements for the quality of work (high accuracy, efficiency, etc.);

- an increase in the responsibility of the functions performed by the system, a high economical and technical cost of failure. 
The calculation of the parameter of the flow of failures of TEM (traction electric machine), electrical equipment, mechanical equipment for the period of operation from 2015 to 2019 was carried out. The data are summarized in a table (table 1-2).

The data of the parameter of the flow of failures of TEM NB-514 according to the operating seasons are given (Figure 2). For comparison, an analysis was taken of the repair plant UE "O'ztemiryo'lmashta'mir, "depot Uzbekistan, Tinchlik, Karshi.

When considering the dependences of changes in the TEM (traction electric machine) failure flows of the "O'zbekiston temir yo'ullari" "UzRW" electric locomotives, it can be noted:

- decrease in the reliability of insulation during operation;

- the parameter of the flow of insulation failures grows;

- there are significant changes in the seasons of operation;

- failures of TEM (traction electric machine) anchors with open frontal parts grow;

- an increase in the nature of the flow of failures of the main, additional poles, and the compensation winding, since often traction motors operate for a long time with currents exceeding the nominal value, which leads to more intensive aging of the insulation.

The increased number of failures of insulating structures, especially the NB-514 electric machines of the VL80 ${ }^{c}$ electric locomotives, which perform most of the work in freight traffic and UzRW, required a system analysis of the causes of TEM (traction electric machine) failures and, first of all, their insulating structures[18].

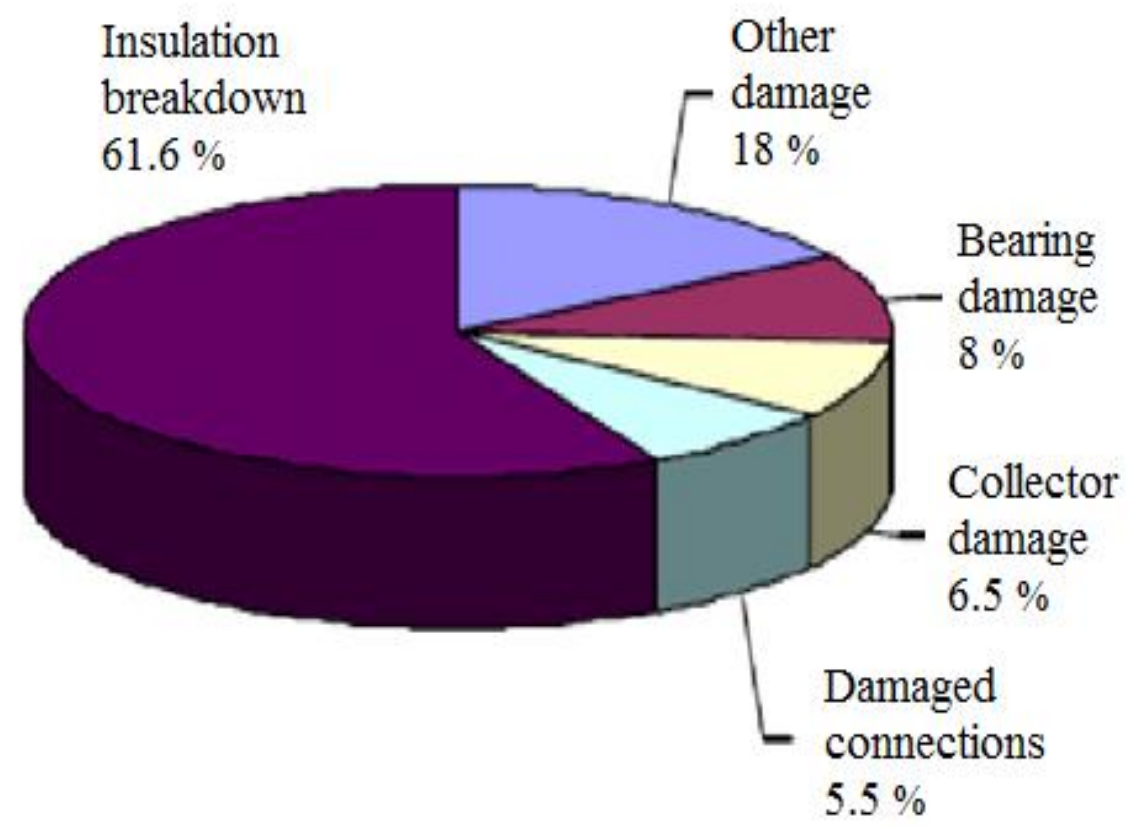

Fig. 2. Distribution of failures of traction electric machines of UzRW electric locomotives by elements in 2019 
Table 1. Types of failures of traction electric motors of UzRW electric locomotives (mi, \%)

\begin{tabular}{|l|c|c|}
\hline \multirow{2}{*}{\multicolumn{1}{|c|}{ Failure and Damage Types }} & \multicolumn{2}{c|}{ Engine's type } \\
\cline { 2 - 3 } & HB-418 kb & HB-514 \\
\hline $\begin{array}{l}\text { Insulation breakdowns and turn-to- } \\
\text { turn short-circuits of armature } \\
\text { windings }\end{array}$ & 14.2 & 20.1 \\
\hline $\begin{array}{l}\text { Insulation breakdown of the main } \\
\text { poles (MP) }\end{array}$ & 11.5 & \\
\hline $\begin{array}{l}\text { Insulation breakdown of additional } \\
\text { poles (AP) }\end{array}$ & 3.4 & 28.2 \\
\hline $\begin{array}{l}\text { Insulation breakdowns of } \\
\text { compensation windings (CW) }\end{array}$ & 3.1 & 10.1 \\
\hline Damaged MP connections & 1.26 & 3.48 \\
\hline Damaged AP connections & 4.92 & 1.57 \\
\hline Damaged CW connections & 1.29 & 2.14 \\
\hline Damage to the brush holder bridges & 0.9 & 1.32 \\
\hline Damaged output cables & 1.28 & 1.04 \\
\hline Smelting headers of collectors & 6.51 & 1.07 \\
\hline Damage to traverse brackets & 2.24 & 0.6 \\
\hline Destruction of anchor bands & 4.78 & 1.03 \\
\hline Damaged motor armature bearings & 11.47 & 0.68 \\
\hline Wreck damage & 12.89 & 12.3 \\
\hline Damage to the collector surface & 1.41 & 6.2 \\
\hline
\end{tabular}

Table 2. Failures of TEM (traction electric machine) of UzRW electric locomotives in 2019

\begin{tabular}{|c|c|c|c|c|c|}
\hline $\begin{array}{c}\text { TEM } \\
\text { types }\end{array}$ & $\begin{array}{c}\text { Failures } \\
\text { Num. }\end{array}$ & $\begin{array}{c}\text { Mileage, } \\
10^{6} \mathrm{~km}\end{array}$ & $\begin{array}{c}\omega, \text { renouncement } \\
10^{6} \mathrm{~km}\end{array}$ & $\begin{array}{c}\text { TEM } \\
\text { number in } \\
\text { operation, } \\
\text { num. }\end{array}$ & $\begin{array}{c}\text { Percent } \\
\text { faulty } \\
\text { TEM }\end{array}$ \\
\hline NB-514 & 38 & 498859 & 6.4 & 208 & 0.12 \\
\hline NB-418K6 & 62 & 173774 & 12.3 & 254 & 0.20 \\
\hline NB-412K & 13 & 84489 & 5.2 & 144 & 0.09 \\
\hline Total & 213 & 757122 & 7.6 & 606 & 0.11 \\
\hline
\end{tabular}

\section{Conclusions}

And the results of the analysis on the reliability of TEM (traction electric machine) of electric locomotives of the railways of the Republic of Uzbekistan, carried out by us over the past five years, indicate an increase in failures several times. Studies have shown that the reliability of NB-514 engines is almost one and a half times higher than NB-418K6. Failures of engines NB-418K6 of the "southern direction" of the Uzbekistan Railways (UzRW) (repair plant "Uztemiryulmashtamir," depot Uzbekistan, Tinchlik are more than 1.5 times higher than failures of engines of the same type of electric locomotives. 
It was found that the parameter of the flow of failures is unevenly distributed over the operating time. The lowest reliability of TEM (traction electric machine) is observed in the summer period of operation and during the transition of the ambient air temperature through $+50^{\circ} \mathrm{C}$ value.

Uneven overheating of the insulation of the open frontal part of the armature winding leads to a local decrease in the reliability of this part of the TEM (traction electric machine). In the process of weakening the bonding layer of the insulation of the rear frontal part, moisture through the porous capillaries penetrates into the armature groove. Most of the malfunctions with the most common diagnosis on the railways of the Republic of Uzbekistan "anchor-zero" are due to this reason.

\section{References}

1. Smirnov V.P. Continuous temperature control of extremely loaded equipment of an electric locomotive: monograph, Publishing House. state un-ty, p. 328, (2003)

2. Khudonogov A.M. Analysis of the reliability of the insulation of the windings of electric machines of traction rolling stock taking into account the peculiarities of the climatic conditions of the external environment.

3. Khudonogov D.A. Olentsevich V.V. Sidorov E.M. Lytkina. Scientific problems of transport in Siberia and the Far East, № 2, pp. 232 - 236, (2009)

4. Protocol № EM-18-15. Thermal tests of the NB-514 traction motor. Unitary Enterprise "Uztemiryulmashtamir", $2019.21 \mathrm{p}$.

5. Protocol № EM-18-15. Thermal tests of the NB-418 traction engine. UE "Uztemiryulmashtamir", p. 23, (2018)

6. Serebryakov A.S. Electrical engineering materials science. Electrical insulating materials: a textbook for higher educational institutions of the railway. Transport / A.S. Serebryakov, p. 280, M.: Route, (2005)

7. Ismailov Sh.K. Electrical strength of insulation of electric machines of locomotives: monograph, Omsk state. University of Railways, p. 272, (2013)

8. Ivanov V.N. Reliability of electric machines of traction rolling stock, Scientific problems of transport in Siberia and the Far East, № 1, pp. 196-198, (2008)

9. Olentsevich D.A. Improvement of the system of technical maintenance of insulation of traction motors of electric locomotives, Irkutsk, 2010 p. 146 p.

10. Analysis of the technical condition of the electric locomotive fleet along the railway network of Uzbekistan for 2009, p. 74 Moscow, (2018)

11. Khudonogov A.M. Restoration of the insulation properties of the armature windings of the traction electric motor, Bulletin of ISTU 4 (28), pp. 60 - 62. (2006)

12. Konovalenko D.V. Rational modes of drying of humidified insulation of windings of traction electric machines, p. 193, Irkutsk, (2007)

13. Instructions for preparation for work and maintenance of electric locomotives in winter and summer conditions; TsT / 814 from 10.04.14. - T.: Transport, p. 72, (2014)

14. Order on the system of maintenance and repair of locomotives of JSC "UzRW" No. $3 \mathrm{r}$, dated 06.01.2016

15. TsT-TsTVR / 4782. Rules for the repair of electric vehicles of electric rolling stock; $p$. 356, Moscow, Transport, (1975)

16. Rakutko, S.A. Determination of the protective angle of a luminaire with arbitrary light distribution and its influence on the quality of the generated lighting, Materials of the All-Russian scientific-practical conference "Actual problems of the agro-industrial complex". Ulyanovsk State Agricultural Academy. - Ulyanovsk, pp. 168-173, (2008) 
17. Lytkina E.M. Increasing the efficiency of encapsulating the insulation of the windings of traction motors of electric locomotives with infrared radiation, p. 204, Khabarovsk, (2011)

18. Makarov V.V. Resource-saving principles of drying technology for moist insulation of electrical equipment EPS, Khabarovsk: FESTU, 1. pp. 32-37, (2001)

19. Grishchenko A.V. Electric machines and converters of rolling stock, Moscow, ACADEMA, p. 258, (2005)

20. Daylidko A.A. Electric car, M.: Educational and methodical office of MPS Russia, p. 37, (2002)

21. Dubrovsky Z.M. Popov V.I. Directory. Freight electric locomotives of alternating current, p. 55, Moscow, (1991) 